\title{
Radiation Retinopathy-A Review of Past and Current Treatment Strategies
}

\author{
Hannah J Yư and Amy C Schefler ${ }^{1,2}$ \\ 1. Retina Consultants of Houston, Houston, TX, USA; 2. Blanton Eye Institute, Houston Methodist Hospital, Houston, TX, USA
}

DOI: https://doi.org/10.17925/USOR.2020.13.1.34

$\mathrm{R}$ adiation retinopathy is a common and devastating visual side effect of radiation therapy for uveal melanoma and other ocular cancers. While the Collaborative Ocular Melanoma Study demonstrated that plaque brachytherapy is a great alternative for treatment of ocular cancers, many patients develop a visual acuity of 20/200, or worse, with rare improvement after observation of disease. This poor vision emerges from radiation scatter, which can cause damage to the retina and the optic nerve with symptoms similar to other retinal vascular diseases, such as diabetic retinopathy and neovascular age-related macular degeneration. Disease symptoms can develop between 6 months and 3 years post-treatment. Several treatment options have been explored to slow or stop the progression of this retinopathy, including laser, surgical, and pharmacological treatments. Nevertheless, despite the significant visual loss caused by radiation retinopathy, there are currently no US Food and Drug Administration-approved treatments for the disease. This article will review the history of radiation retinopathy treatment and discuss recent prospective studies in anti-vascular endothelial growth factor treatment.

\section{Keywords}

Radiation retinopathy, uveal melanoma, anti-vascular endothelial growth factor, ocular cancer, intravitreal injection, brachytherapy

Disclosure: Amy Schefler has received research grants from Aura, Optos, Genentech, Regeneron, and Castle Biosciences. She is also a consultant for Aura, Optos, Genentech, and Castle Biosciences. Hannah Yu has no financial or non-financial relationships or activities to declare in relation to this article.

Review Process: Double-blind peer review.

Compliance with Ethics: This study involves a review of the literature and did not involve any studies with human or animal subjects performed by either of the authors.

Authorship: The named authors meet the International Committee of Medical Journal Editors (ICMJE) criteria for authorship of this manuscript, take responsibility for the integrity of the work as a whole, and have given final approval for the version to be published.

Access: This article is freely accessible at touchOPHTHALMOLOGY.com

(C) Touch Medical Media 2020

Received: March 5, 2020

Accepted: May 5, 2020

Published Online: May 21, 2020

Citation: US Ophthalmic Review. 2020;13(1):34-9

Corresponding Author: Amy C Schefler, 6560 Fannin St., Suite 750, Houston, TX 77030 , USA. E: acsmd@houstonretina.com

Support: No funding was received in the publication of this article.
Radiation retinopathy is a common and slowly progressive visual side effect of radiation therapy, such as brachytherapy, external beam radiotherapy, proton beam radiation, helium ion radiotherapy, and gamma knife radiotherapy for uveal melanoma and other intraocular or orbital cancers. ${ }^{1-6}$ Patients treated with radiation therapy for cancers of the head and neck can also develop radiation-related retinopathy. Although the lens normally functions to prevent damaging wavelengths of light and radiation from reaching the retina, therapeutic doses with scatter to the retinal vasculature can cause radiation retinopathy with onset typically occurring between 6-months and 3-years post-radiation therapy, with devastating visual outcomes. ${ }^{8}$ Following the Collaborative Ocular Melanoma Study (COMS), which reported similar mortality rates after radiotherapy and enucleation for choroidal melanoma, ${ }^{9-11}$ radiotherapy became the primary treatment for ocular cancers. While radiotherapy offers an eye-sparing alternative for patients and allows them to maintain some level of visual acuity, COMS also reported that at 3 years post-treatment, nearly $50 \%$ of patients had a visual acuity of 20/200 or worse. ${ }^{12}$ Improvement in visual acuity was rare after observation of poor vision.

Radiation retinopathy is a broad term that can refer to both non-proliferative and proliferative radiation retinopathy as well as radiation maculopathy. It includes all retinal vascular changes caused by radiation therapy which can lead to variable clinical findings. In addition, while several treatment options have been explored with both retrospective studies and prospective trials, there is no widespread standard for the treatment of radiation retinopathy. Due to its similarities with other retinal vascular diseases, such as diabetic retinopathy and neovascular age-related macular degeneration, several recent prospective studies have utilized anti-vascular endothelial growth factor (VEGF) injections for radiation retinopathy treatment. However, the challenge for this group of patients is to establish the best practice patterns for the frequency and duration of injections needed in order to maintain visual acuity in the long term. This article comprises a review of the history of radiation retinopathy treatment and the current strategies being studied by investigators.

\section{Etiology and clinical features}

Radiation therapy, such as local plaque brachytherapy treats a variety of cancers by directly damaging the DNA of rapidly dividing tumor cells, and by the indirect creation of free radicals that cause extensive damage to cellular structures. However, this damage, both direct and indirect, affects not only tumor cells, but surrounding healthy tissue as well. In the case of ocular cancers, or those in nearby areas, radiation therapy can result in retinal vascular endothelial cell loss and inflammation. ${ }^{13}$ This leads to a catastrophic domino effect on the retinal vasculature. ${ }^{1,14}$ Over time, the damaged capillaries close, inducing retinal ischemia and neovascularization. Eventually, closure of large retinal vessels can also be seen on fluorescein angiography. ${ }^{15,16}$ 
Figure 1: A 63-year-old male treated with proton beam radiation for uveal melanoma in the right eye

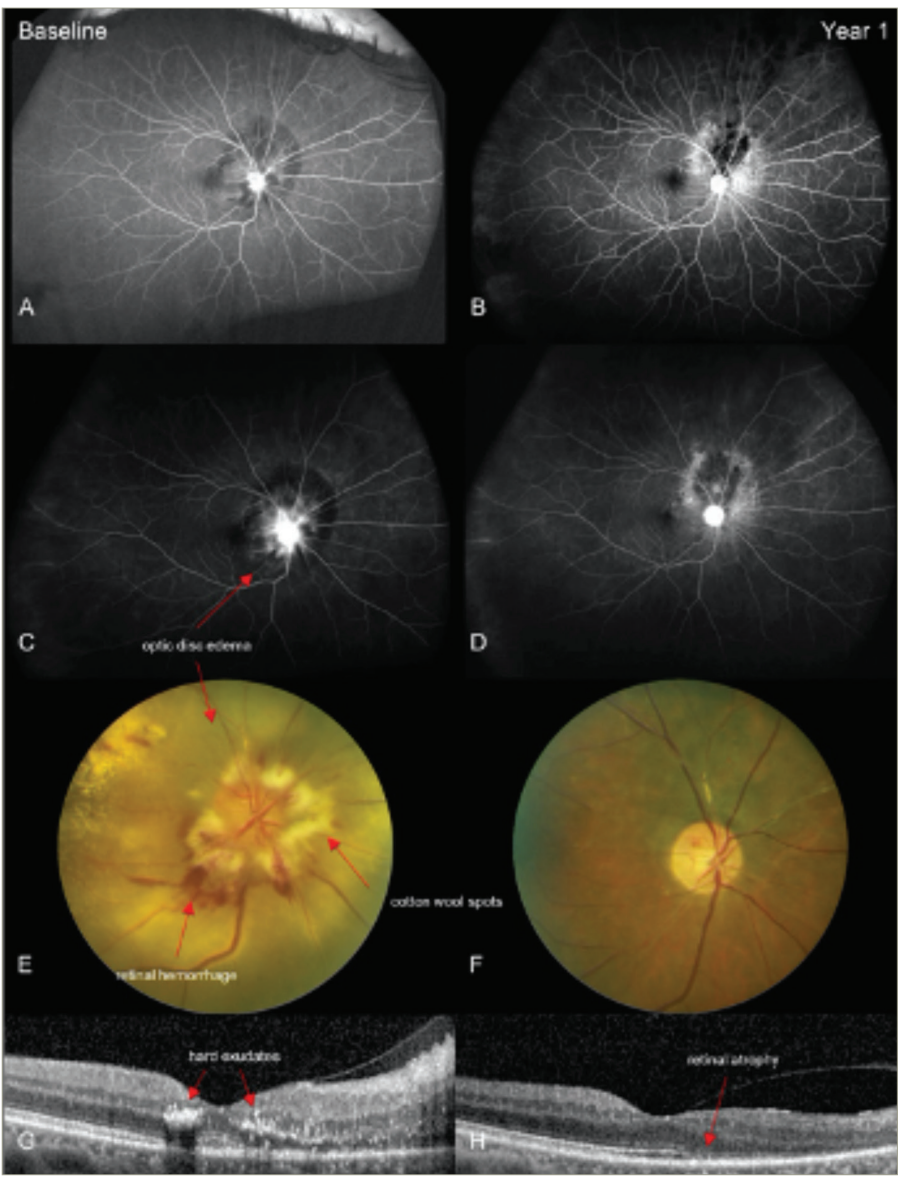

The patient presented approximately 1 year later with optic disc edema, retinal hemorrhages, cotton-wool spots, hard exudates, and visual acuity 20/60 (A, C, E, and G) After treatment with targeted panretinal photocoagulation and monthly ranibizumab for 1 year, he presented with improved exudates, retinal atrophy, improved optic disc edema, and visual acuity 20/32 (B, D, F, and $H)$.

Radiation retinopthy typically presents upon exam with any combination of the following clinical findings: macular edema, optic disc edema, telangiectasias, microaneurysms, cotton-wool spots, hard exudates, capillary non-perfusion, and retinal pigment epithelia (RPE) atrophy (Figure 1) - representing clinical overlap with diabetic retinopathy. In both radiation and diabetic retinopathy, a non-proliferative classification is typically seen in the beginning stages of the disease, with advancement to proliferative disease in severe cases. In proliferative radiation retinopathy, growth factors including fibroblast, epithelial, platelet-derived, and VEGF are released by epithelial and endothelial cells and fibroblasts in order to mediate the tissue repair process in the ischemic and non-perfused tissues.,31,17 In retinal vasculature, these growth factors induce neovascularization, causing fluid leakage and subsequent vision loss. Further complications of proliferative radiation retinopathy can include vitreous hemorrhage, neovascular glaucoma, optic neuropathy, optic nerve papillopathy, vitreous hemorrhage, and tractional retinal detachment. Ocular side effects of radiation not typically present in diabetic retinopathy include atrophy of the RPE and optic atrophy. ${ }^{1}$

\section{Prevalence and risk factors}

Primary intraocular and orbital cancers are relatively uncommon diseases, and secondary metastases to the eye are rare, but more common than primary tumors. In 2020, an estimated total 2,000 adults will be diagnosed with uveal melanoma, the most common primary intraocular cancer in the USA, with an approximate $28 \%$ 5-year mortality rate. ${ }^{18}$ Most small and medium-sized tumors ( $\leq 10 \mathrm{~mm}$ in height or $\leq 16 \mathrm{~mm}$ in largest base diameter) are treated with radiation therapy, while most large tumors (>10 $\mathrm{mm}$ in height or $>16 \mathrm{~mm}$ in largest base diameter) are treated solely by enucleation. ${ }^{19}$ Following radiation therapy, a significant proportion of patients will develop radiation retinopathy within 5 years. A study by Gündüz et al. reported that $42 \%$ of patients treated for posterior uveal melanoma developed non-proliferative radiation retinopathy within 5 years of treatment. ${ }^{20}$ Krema et al. further reported that $30 \%$ of patients treated for melanoma with plaque brachytherapy developed evidence of radiation retinopathy within 2 years of treatment. ${ }^{4}$ Radiation retinopathy has also been noted as a side effect of radiation therapy for head and neck cancers. In a study by Parsons et al., 26 of 68 patients treated with external beam radiation for primary head and neck cancers developed radiation retinopathy in at least one eye within 3 years. ${ }^{21}$

Although a meaningful proportion of patients develop evidence of retinopathy following radiation therapy, the risk of disease can increase or decrease depending on specifications of radiation therapy; type of radiation, isotope, radiation dose, and fractionation schedule can all affect the degree of retinopathy. ${ }^{21-30}$ For brachytherapy, several isotopes have been utilized to treat ocular cancers, some carrying higher risk of radiation damage compared with others. ${ }^{30}$ Cobalt-60 was one of the first isotopes used in the 1960s and 1970s, but due to high energy and ineffective shielding, significant radiation side effects were observed on adjacent retinal structures. Subsequently, other isotopes were explored for use in brachytherapy to reduce the risk of retinopathy such as palladium-103, strontium-90, ruthenium-106, and iodine-125. Today, ruthenium-106 is the most commonly used isotope in Europe for the treatment of uveal melanoma, while iodine-125 is the most commonly used in the USA. Ruthenium-106 has been shown to have excellent tumor control rates with limited depth of penetration, resulting in less radiation exposure to undesired retinal structures. ${ }^{30,31}$ While iodine-125 has similarly excellent tumor control rates for small and medium tumors, studies have shown meaningful radiation damage to the retina following treatment, resulting in significant rates of radiation retinopathy in the USA. ${ }^{30,31}$

Risk of retinopathy is also dependent on radiation dose and fractionation schedule. For head and neck cancers treated with external beam radiation, radiation retinopathy is typically not observed with a total dose <45 Gy $(4,500 \mathrm{rad})$ to the retina and optic nerve, though incidence steadily increases with increased dosage. ${ }^{21}$ When possible, hyperfractionation has been demonstrated to decrease the risk of radiation retinopathy development. ${ }^{27}$

Risk of disease is also influenced by tumor characteristics and patient demographics. ${ }^{32-34}$ For example, the risk of disease is increased for patients with diabetes mellitus and other disorders that may damage the vasculature, such as hypertension and coronary artery disease. ${ }^{32-34}$ Additionally, eyes with larger tumors may require high doses of radiation in close proximity to the macula or optic disc, increasing the chance of developing radiation retinopathy. ${ }^{35}$ Specifically, eyes receiving $>50$ Gy $(5,000 \mathrm{rad})$ to $>60 \%$ of the retina or to the critical structures of the eye such as the optic disc or macula are at significant risk for developing radiation-related vision loss in the form of radiation optic neuropathy or radiation retinopathy. ${ }^{23}$ 


\section{History of radiation retinopathy treatment}

Currently, there is no widely accepted treatment strategy for visual stabilization or improvement in patients with radiation retinopathy. However, due to the similarities with the pathophysiology of diabetic retinopathy, similar treatments have been utilized by clinicians to prevent visual loss for patients, post-radiation therapy. The use of laser photocoagulation and intravitreal injections has been studied considerably, with both retrospective and prospective approaches.

Laser photocoagulation has been used to treat macular edema from non-proliferative and proliferative radiation retinopathy, but with disappointing long-term results. Focal and grid laser have been shown to improve edema and result in better vision than eyes not treated with laser, but vision was still lost compared with baseline acuity. ${ }^{36}$ In a study by Hykin et al., vision and edema showed an initial improvement 6 months after treatment, but the improvement was unsustainable at 12 and 24 months. $^{37}$ Panretinal photocoagulation has also shown regression of neovascularization in proliferative radiation retinopathy, but with poor long-term visual acuity. ${ }^{38}$ Verteporfin photodynamic therapy has also shown success in improving edema, neovascularization, and visual acuity. ${ }^{39-41}$

With the widespread adoption of intravitreal injections for retinal diseases such as diabetic macular edema, neovascular age-related macular degeneration, and retinal vein occlusion, clinicians began experimenting with these pharmacotherapies for radiation retinopathy several years ago. Steroids such as triamcinolone acetonide and the dexamethasone slow release implant have been reported to improve or stabilize visual acuity and decrease retinal thickness in some patients. ${ }^{42-48}$ Several studies have reported on the effectiveness of triamcinolone acetonide in the treatment of radiation retinopathy, but no large-scale study has reported the long-term visual acuity outcomes of this treatment. ${ }^{42-44,48}$ As for dexamethasone, its use in the treatment of radiation-induced macular edema has only been reported in small case series and requires further study. ${ }^{45-47}$

Anti-VEGF agents, however, have had the most success in treating the effects of radiation retinopathy and have become the main focus for radiation retinopathy treatment approaches. In retrospective studies and case series, bevacizumab, ranibizumab, and aflibercept, all commonly used in the treatment of other retinal diseases, have been shown to improve visual acuity and decrease central subfield thickness in a higher proportion of patients than historical controls. ${ }^{49-56}$ However, many of these studies also demonstrated that discontinuation of treatment with anti-VEGF commonly resulted in recurrence of macular edema and regression of visual acuity, suggesting that long-term therapy is necessary for durable results. Additionally, some studies have reported that although anti-VEGF injections decrease neovascular complications from radiation retinopathy, this clinical improvement may not translate into a visual benefit. ${ }^{57-61}$

Several groups have also examined the ability to prevent the development of radiation retinopathy with prophylactic treatment. Finger and Kurli reported a case series of 16 patients who received prophylactic panretinal photocoagulation with a mean follow-up of 16.5 months from laser and 23.2 months from plaque therapy and reported that three (19\%) of the patients developed retinopathy. ${ }^{62}$ A retrospective evaluation of prophylactic bevacizumab injections by Shah et al. reported significant benefits compared with a control group. ${ }^{63}$ In this study, the treatment group received intravitreal bevacizumab at the time of plaque removal and every
4 months for 2 years. At 2 years, $16 \%$ of patients treated with preventative bevacizumab demonstrated clinically evident radiation maculopathy compared with $31 \%$ in the control group. By the end of study, $15 \%$ of treated patients demonstrated poor visual acuity compared with $28 \%$ of control patients. In 2019, Shields et al. reported another retrospective study with the same prophylactic treatment regimen as Shah et al., with mean follow-up of 40 months for the treatment group. ${ }^{64}$ At every time point, those treated prophylactically had less evidence of radiation maculopathy compared with historical controls with no treatment. In a study by Horgan et al., patients prospectively treated with prophylactic triamcinolone acetonide showed a significantly decreased risk of developing macular edema compared with a control group. ${ }^{65} \mathrm{~A}$ pilot study by Materin et al. examined a combination of triamcinolone acetonide and panretinal photocoagulation to prevent edema after plaque radiotherapy, and demonstrated cystoid macular edema rates of $17 \%$ and $24 \%$ at 12 and 24 months, respectively. ${ }^{66}$

Surgical prophylaxis has also been studied for the prevention of radiation retinopathy. McCannel and McCannel reported on the use of pars plana vitrectomy and silicone oil injection at the time of plaque application to attenuate the radiation scatter to surrounding healthy tissues. ${ }^{67}$ With an average follow-up time of 22.1 months in 20 patients, the authors reported lower rates of abnormal maculas (defined as any macula with retinal hemorrhage, exudates, cotton-wool spot, RPE changes, subretinal fluid, or intraretinal fluid) and lower central macular thickness in the patients with pars plana vitrectomy and silicone injection compared with those with normal plaque placement without silicone oil. Adverse effects of surgery such as retinal detachments, tears, macular holes and macular puckers were observed.

\section{Prospective anti-vascular endothelial growth factor trials}

Despite growing evidence that anti-VEGF can potentially treat radiation retinopathy, there is currently no US Food and Drug Administration (FDA)-approved therapy for the disease. As discussed, a multitude of studies have demonstrated the efficacy of anti-VEGF treatment for radiation retinopathy. However, due to the retrospective nature of these studies, the data is not as meaningful as results from prospective studies. Recently, several major prospective trials have made headway in further investigating, more rigorously, the tolerability and efficacy of anti-VEGF agents in the prevention and treatment of non-proliferative and proliferative radiation retinopathy (Table 1).

\section{Ranibizumab}

Currently, there are three published prospective trials examining the treatment of radiation retinopathy with ranibizumab. A phase I/II open-label, non-randomized, prospective trial by Finger et al. studied the safety and efficacy of high-dose $(2.0 \mathrm{mg}$ ) ranibizumab in 10 eyes with persistent radiation retinopathy from either external beam radiation or plaque brachytherapy characterized by macular edema or leakage upon standard dose anti-VEGF. ${ }^{68}$ Over the course of the study, three patients demonstrated worsening retinopathy, but treatment was generally well tolerated with no severe adverse reactions. By month $12,70 \%$ of subjects had stable best-corrected visual acuity (BCVA) and $80 \%$ had significantly reduced central foveal thickness with an average reduction of $19.3 \%$. Therefore, although anatomical benefits were observed from high-dose ranibizumab, significant visual effects were not proven, but the study was likely not powered to detect a difference. These results were consistent with studies 
Table 1: Comparison of prospective anti-vascular endothelial growth factor trials

\begin{tabular}{|c|c|c|c|c|}
\hline $\begin{array}{l}\text { Author } \\
\text { (year) }\end{array}$ & Inclusion criteria & Cohorts/interventions & $\begin{array}{l}\text { Length of } \\
\text { study }\end{array}$ & Main outcomes \\
\hline $\begin{array}{l}\text { Finger et al. } \\
(2013)^{68}\end{array}$ & $\begin{array}{l}\text { Patients with recalcitrant RM that failed } \\
\text { treatment with anti-VEGF }\end{array}$ & $\begin{array}{l}\text { Cohort } \mathbf{1}(\mathbf{n}=\mathbf{5}) \text { : high-dose }(2.0 \mathrm{mg}) \text { ranibizumab } \\
\text { every } 30 \text { days } \\
\text { Cohort } \mathbf{2}(\mathbf{n}=\mathbf{5}) \text { : high-dose }(2.0 \mathrm{mg}) \text { ranibizumab } \\
\text { every } 30 \text { days for } 4 \text { months, } \\
\text { PRN thereafter }\end{array}$ & 12 months & $\begin{array}{l}70 \% \text { of patients with stable or improved BCVA; } \\
80 \% \text { with significant improvement in CFT }\end{array}$ \\
\hline $\begin{array}{l}\text { Kim et al. } \\
(2016)^{3}\end{array}$ & $\begin{array}{l}\text { Patients with choroidal melanoma } \\
\text { located within } 2 \text { disc diameters of } \\
\text { the optic nerve and/or macula with } \\
\text { no evidence of RR, history of retinal } \\
\text { vasculopathy or systemic anti-VEGF }\end{array}$ & $\begin{array}{l}\text { Cohort } \mathbf{1}(\mathbf{n}=\mathbf{2 0}): 0.5 \mathrm{mg} \text { prophylactic } \\
\text { ranibizumab every } 2 \text { months } \\
\text { Cohort } \mathbf{2}(\mathbf{n}=\mathbf{2 0}): 0.5 \mathrm{mg} \text { or } 1.0 \mathrm{mg} \text { prophylactic } \\
\text { ranibizumab every } 2 \text { months }\end{array}$ & 22 months & $\begin{array}{l}97 \% \text { of treated patients with VA } \geq 20 / 200,45 \% \\
\text { in historical controls; } 33 \% \text { of patients with } \\
\text { small/medium tumors had evidence of radiation } \\
\text { maculopathy by EOS, } 68 \% \text { of historical controls }\end{array}$ \\
\hline $\begin{array}{l}\text { Fallico et al. } \\
(2019)^{74}\end{array}$ & $\begin{array}{l}\text { Patients with treatment-naiive RM } \\
\text { (Horgan's grade }=3-5 \text { ) secondary to } \\
\text { Ru-106 brachytherapy for choroidal } \\
\text { melanoma }\end{array}$ & $\begin{array}{l}\text { Cohort } 1(\mathbf{n}=9): 2.0 \text { mg aflibercept monthly until } \\
\text { maximum VA was achieved and/or there were no } \\
\text { signs of ME on OCT; PRN thereafter }\end{array}$ & 24 months & $\begin{array}{l}\text { Mean of } 4.4 \text { injections given; mean BCVA } \\
\text { significantly improved by EOS; CFT } \\
\text { significantly decreased }\end{array}$ \\
\hline $\begin{array}{l}\text { Murray et al. } \\
(2019)^{75}\end{array}$ & $\begin{array}{l}\text { Patients with treatment-naive RM from } \\
\text { radiation therapy of uveal melanoma } \\
\text { with a measurable decline in BCVA }\end{array}$ & $\begin{array}{l}\text { Cohort } 1(\mathrm{n}=\mathbf{2 0}): 2.0 \mathrm{mg} \text { aflibercept every } \\
6 \text { weeks } \\
\text { Cohort } \mathbf{2} \text { ( } \mathrm{n}=\mathbf{2 0}): 2.0 \mathrm{mg} \text { aflibercept and } \\
\text { treat-and-adjust thereafter (1-week adjustments) }\end{array}$ & 60 weeks & $\begin{array}{l}\text { 5\% of eyes with BCVA of 20/200 or worse by } \\
\text { week 60; significant improvement in CRT by EOS; } \\
\text { no significant differences in injection frequency } \\
\text { between cohorts }\end{array}$ \\
\hline $\begin{array}{l}\text { Schefler et al. } \\
(2020)^{71}\end{array}$ & $\begin{array}{l}\text { Patients with treatment-naïve RR-related } \\
\text { ME with a history of brachytherapy, } \\
\text { EBRT, or proton beam therapy }\end{array}$ & $\begin{array}{l}\text { Cohort } 1 \text { ( } n=8 \text { ): } 0.5 \text { mg ranibizumab monthly for } \\
12 \text { months; treat-and-extend thereafter } \\
\text { Cohort } 2 \text { ( } n=16): 0.5 \text { mg ranibizumab } \\
\text { monthly and TRP } 1 \text { week after first injection } \\
\text { for } 12 \text { months; treat-and-extend thereafter } \\
\text { Cohort } \mathbf{3} \text { ( } \mathbf{n}=16): 0.5 \mathrm{mg} \text { ranibizumab monthly } \\
\text { and TRP } 1 \text { week after first injection for three } \\
\text { loading doses, then PRN for } 12 \text { months; } \\
\text { treat-and-extend thereafter }\end{array}$ & 24 months & $\begin{array}{l}\text { 97\% of patients with BCVA } 20 / 400 \text { or better by } \\
\text { EOS; most significant visual gains in the monthly } \\
\text { cohort; no visual or anatomic benefit in cohorts } \\
\text { with TRP }\end{array}$ \\
\hline $\begin{array}{l}\text { Schefler et al. } \\
(2019)^{77}\end{array}$ & $\begin{array}{l}\text { Patients with treatment-naïv RR from } \\
\text { radiation for ocular or orbital cancer } \\
\text { with retinal fluid causing vision loss }\end{array}$ & $\begin{array}{l}\text { Cohort } 1 \text { ( } \mathbf{n = 1 5} \text { ): Four monthly loading } \\
\text { doses of } 2.0 \text { mg aflibercept; treat-and-extend } \\
\text { protocol thereafter } \\
\text { Cohort } 2 \text { ( } \mathbf{n = 1 5 ) :} 2.0 \mathrm{mg} \text { aflibercept with treat- } \\
\text { and-extend protocol }\end{array}$ & 52 weeks & Results to be announced \\
\hline
\end{tabular}

$B C V A=$ best-corrected visual acuity; $C F T=$ central foveal thickness; $C R T=$ central retinal thickness; $E B R T=$ external beam radiation therapy; $E O S=$ end of study; $M E=$ macular edema; $O C T=$ optical coherence tomography; $P R N=$ pro re nata (as needed); $R M=$ radiation maculopathy; $R R$ = radiation retinopathy; $R U$ = ruthenium-106; $S A E=$ serious adverse events; $T R P=$ targeted retinal photocoagulation; VA = visual acuity; VEGF = vascular endothelial growth factor .

of high-dose ranibizumab for recalcitrant age-related macular degeneration, in which an initial improvement in visual acuity was seen, but long-term visual acuity improvements compared with typical dose ranibizumab were not realized. ${ }^{69}$ Likely, the pharmacology of the drug and the need for redosing despite the dose, account for the limitations of this approach.

Kim et al. demonstrated the use of prophylactic ranibizumab for the prevention of radiation retinopathy with a prospective, phase I, open-label, randomized study of 40 high-risk patients, in which intravitreal ranibizumab treatment was initiated immediately after proton beam irradiation for choroidal melanoma, prior to clinical evidence of radiation maculopathy. ${ }^{3}$ Fifteen large tumors and 25 small/medium tumors were treated with $0.5 \mathrm{mg}$ or $1.0 \mathrm{mg}$ ranibizumab every 2 months for 22 months, beginning with an initial injection at the time of tumor localization surgery. Thirty-two patients completed the month-24 visit, with 30/31 (97\%) patients with a visual acuity of $20 / 200$ or better compared with $45 \%$ of historical controls. Eight of the 24 (33\%) patients with small/medium tumors showed evidence of radiation maculopathy at month 24 compared with $68 \%$ of controls. Three patients with large tumors died after developing metastases, but no serious ocular or systemic adverse events related to ranibizumab were observed.

In this study, Kim et al. attempted the prevention of radiation retinopathy development, a so-called prophylactic approach. For patients receiving radiotherapy for ocular tumors or head/neck tumors, it is possible that such a prophylactic approach could be key in preserving long-term vision. Early data from the diabetic retinopathy literature suggest that at least in the short term (up to 2 years), such an approach may be biologically beneficial. ${ }^{70}$ Since radiation retinopathy has a relatively long latency period between the conclusion of radiotherapy and the onset of retinal disease, it can be logistically difficult and anxiety-provoking for patients to constantly monitor for the early stages of retinopathy and wait for a visual decline in 
order to initiate treatment. A prophylactic approach would standardize the approach to this disease for all patients and potentially save vision in the long term. Additional larger, multicenter studies with significant long-term follow-up are needed to definitively answer these critical questions.

Another recent prospective trial by schefler et al. studied three different treatment methods of radiation retinopathy with ranibizumab. ${ }^{71}$ Cohorts $A$ and $B$ both received monthly ranibizumab, but one week after the first injection, cohort $\mathrm{B}$ also received targeted retinal photocoagulation (TRP) to areas of peripheral retinal ischemia. Cohort $\mathrm{C}$ received three consecutive loading doses of monthly ranibizumab and was then only treated as needed (PRN). In addition, cohort $\mathrm{C}$ received TRP 1 week after the first injection. Beginning at week 52, all three cohorts were switched to a standardized treat-and-extend regimen for 48 additional weeks. Overall, at the end of year 1, all three cohorts had significantly better visual outcomes than historical controls. Cohort A showed significantly better visual gains from baseline to year 1 compared with cohort C. Year 2 results are pending publication, but initial national presentations on the subject have indicated that the visual gains in all three groups from year 1 were attenuated in year 2 as injections were given less frequently.

The results of this study mirrored the results of many previous analyses that demonstrated improved efficacy of monthly anti-VEGF compared with PRN regimens. ${ }^{72}$ Interestingly, TRP also did not appear to benefit this radiation retinopathy population, consistent with results of the effect of TRP on frequency injection in patients with diabetic retinopathy. ${ }^{73}$ All three cohorts did, however, have an improvement in central macular thickness over time in addition to significant improvements in other anatomic changes associated with radiation retinopathy. Although this study did have limitations such as a relatively small number of patients and a lack of a true control group, it is one of the larger prospective, randomized trials that has studied anti-VEGF for radiation retinopathy.

\section{Aflibercept}

Recently, two prospective trials examined the role of intravitreal aflibercept in treating macular edema associated with radiation maculopathy and potentially improving visual acuity outcomes. Fallico et al. recruited nine subjects with radiation-related macular edema following plaque brachytherapy. ${ }^{74}$ Subjects were treated with monthly $2.0 \mathrm{mg}$ intravitreal aflibercept until maximum visual acuity was observed and/or there were no signs of edema on optical coherence tomography (OCT), then treated PRN through month 24. An average of 4.4 injections were given. By the end of the study, mean BCVA had significantly improved to $0.56 \operatorname{logMAR}$ (Snellen equivalent 20/80) from 0.90 (20/160) at baseline, and central foveal thickness had significantly decreased from $546 \mu \mathrm{m}$ at baseline to $223 \mu \mathrm{m}$ at month 24. Each subject's maculopathy was also graded by Horgan's OCT-based scale. Overall, subjects showed a marked improvement from baseline to month 24; at baseline, subjects ranged from grade $3-5$, and by month 24 , subjects either had no macular edema or were grade 1 or 2 .

Another recent prospective study by Murray et al. demonstrated the efficacy of aflibercept for radiation maculopathy with two treatment regimens. ${ }^{75}$ Forty patients treated for uveal melanoma with radiation therapy were randomized to a fixed treatment interval of 6 weeks or a treat-and-adjust treatment centered around 6 weeks. Thirty-nine patients completed 1 year of follow-up with significant improvement in mean central retinal thickness from baseline. At study conclusion, only $5 \%$ of eyes showed a BCVA worse than 20/200 and nearly half of treated patients maintained BCVA 20/50 or better. There was no significant difference in the number of injections received between treatment cohorts.

It has been established that for long-term improvements in visual acuity in diseases such as neovascular age-related macular degeneration, diabetic macular edema, and retinal vein occlusion, anti-VEGF injections must be given routinely (as frequently as every 4 weeks) initially for the strongest drying effect on the retina, and a significant percentage of patients cannot maintain a dry macula without long-term routine injections. However, this treatment approach places a heavy economic burden on patients and society. ${ }^{76}$ Long-term, a longer-acting drug or implant would be ideal, and several such devices and therapies under early-phase trials for more common retinal diseases are likely to be effective for radiation retinopathy as well, while decreasing the economic burden on healthcare systems.

Another open-label, randomized, prospective study by schefler et al., which has almost completed enrollment, has been studying the safety of intravitreal $2.0 \mathrm{mg}$ aflibercept administered to two cohorts, both of which will be treated on a treat-and-extend protocol. ${ }^{77}$ Cohort 1, however, will receive 4 monthly loading doses of aflibercept and cohort 2 will receive two loading doses. This study will observe the mean number of injections received from baseline in addition to the percentage of patients with resolved macular edema and stabilized and improved visual acuity.

Both of these prospective studies presented important information about the efficacy of intravitreal aflibercept as a treatment for radiation retinopathy and presented promising results. Like the early results with ranibizumab, validation with larger multicenter studies is imperative.

\section{Conclusion}

Radiation therapy is the most common treatment option for patients with malignant intraocular cancers or cancers of the head and neck. For diseases like uveal melanoma, radiation is an opportunity to avoid enucleation and maintain visual acuity following treatment. However, radiation has many known side effects, and vision loss after radiation can be devastating to patients.

In the past, there has been a complete lack of treatment options for this disease, and over $40 \%$ of patients would experience the devastating vision loss associated with radiotherapy within 3 years of treatment. However, today there are several promising treatment options that can help a large proportion of patients maintain their vision, which can significantly improve a patient's overall quality of life. The rise of anti-VEGF use was revolutionary in the world of retinal medicine for the treatment of diseases such as neovascular age-related macular degeneration, diabetic macular edema, and retinal vein occlusion, and has shown incredible promise in the treatment of radiation retinopathy. However, there are still no FDA-approved treatments specifically for radiation retinopathy and there is still notable ambiguity in the standard of care for those patients affected by the disease. Both retrospective and prospective research into various therapies has made great strides towards understanding the optimal treatment regimens. Nevertheless, further research must still be performed to elucidate the long-term clinical utility of anti-VEGF injections and other therapies for radiation retinopathy. $\square$ 
1. Schachat AP. Ryan's Retina. In: Wilkinson C, Schachat A, Hinton D, et al. (eds). Ryan's Retina, Sixth edition. Amsterdam: Elsevier, 2018;6:1219-26.

2. Finger PT, Chin KJ, Duvall G, Palladium-103 for Choroidal Melanoma Study Group. Palladium-103 ophthalmic plaque radiation therapy for choroidal melanoma: 400 treated patients. Ophthalmology. 2009:116:790-6

3. Kim IK, Lane AM, Jain P, et al. Ranibizumab for the prevention of radiation complications in patients treated with proton beam irradiation for choroidal melanoma. Trans Am Ophthalmol Soc 2016;114:T2.

4. Krema H, Somani S, Sahgal A, et al. Stereotactic radiotherapy for treatment of juxtapapillary choroidal melanoma: 3-year follow-up. Br J Ophthalmol. 2009:93:1172-6.

5. Gragoudas ES, Seddon JM, Egan K, et al. Long-term results of proton beam irradiated uveal melanomas. Ophthalmology. 1987;94:349-53.

6. Haas A, Pinter O, Papaefthymiou G, et al. Incidence of radiation retinopathy after high-dosage single-fraction gamma knife radiosurgery for choroidal melanoma. Ophthalmology. 2002;109:909-13.

7. Bagan SM, Hollenhorst RW. Radiation retinopathy after irradiation of intracranial lesions. Am J Ophthalmol. 1979;88:694-7.

8. Durkin SR, Roos D, Higgs B, et al. Ophthalmic and adnexa complications of radiotherapy. Acta Ophthalmol scand. 2007;85:240-50

9. Diener-West M, Earle JD, Fine SL, et al. The COMS randomized trial of iodine 125 brachytherapy for choroidal melanoma, III: initial mortality findings. COMS Report No. 18. Arch Ophthalmol. 2001:119:969-82

10. Jampol LM, Moy CS, Murray TG, et al. The COMS randomized trial of iodine 125 brachytherapy for choroidal melanoma: IV. Local treatment failure and enucleation in the first 5 years after brachytherapy. COMS report no. 19. Ophthalmology. 2002;109:2197-206

11. Shields $C L$, Naseripour $M$, Carter J, et al. Plaque radiotherapy for large posterior uveal melanomas ( $\geq 8 \mathrm{~mm}$ thick) in 354 consecutive patients. Int J Radiat Oncol. 2003:57:\$447.

12. Melia BM, Abramson DH, Albert DM, et al. Collaborative ocular melanoma study (COMS) randomized trial of $1-125$ brachytherap for medium choroidal melanoma. I. Visual acuity after 3 years COMS report no. 16. Ophthalmology. 2001;108:348-66.

13. Ramakrishnan S, Anand V, Roy S. Vascular endothelial growth factor signaling in hypoxia and inflammation. J Neuroimmune Pharmacol. 2014;9:142-60.

14. Archer DB, Amoaku WM, Gardiner TA. Radiation retinopathy -clinical, histopathological, ultrastructural and experimental correlations. Eye (Lond). 1991;5:239-51.

15. Amoaku WM, Archer DB. Cephalic radiation and retina vasculopathy. Eye (Lond). 1991;5:239-51.

16. Hayreh SS. Post-radiation retinopathy. A fluorescence fundus angiographic study. Br J Ophthalmol. 1970;54:705-14.

17. Crafts TD, Jensen AR, Blocher-Smith EC, Markel TA. Vascular endothelial growth factor: therapeutic possibilities and challenges for the treatment of ischemia. Cytokine. 2015 71:385-93.

18. Cancer.Net. Eye Cancer: Statistics. 2020. Available at: www.cancer net/cancer-types/eye-cancer/statistics (accessed May 6, 2020).

19. Design and methods of a clinical trial for a rare condition: the Collaborative Ocular Melanoma Study. COMS Report No. 3. Control Clin Trials. 1993;14:362-91.

20. Gündüz K, Shields CL, Shields JA, et al. Radiation retinopathy following plaque radiotherapy for posterior uveal melanoma. Arch Ophthalmol. 1999:117:609-14.

21. Parsons JT, Bova FJ, Fitzgerald CR, et al. Radiation retinopathy after external-beam irradiation: analysis of time-dose factors. Int J Radiat Oncol Biol Phys. 1994;30:765-73.

22. Ivvine AR, Alvarado JA, Wara WM, et al. Radiation retinopathy: an experimental model for the ischemic--proliferative retinopathies. Trans Am Ophthalmol SOC. 1981;79:103-22.

23. Takeda A, Shigematsu N, Suzuki S, et al. Late retinal complications of radiation therapy for nasal and paranasal malignancies: relationship between irradiated-dose area and severity. Int J Radiat Oncol Biol Phys. 1999;44:599-605.

24. Wara WM, Irvine AR, Neger RE, et al. Radiation retinopathy. Int J Radiat Oncol. 1979;5:81-3.

25. Chacko DC. Considerations in the diagnosis of radiation injury JAMA. 1981;245:1255-8.

26. Dunavoelgyi R, Zehetmayer M, Gleiss A, et al. Hypofractionated stereotactic photon radiotherapy of posteriorly located choroida melanoma with five fractions at ten Gy - clinical results after six years of experience. Radiother Oncol. 2013;108:342-7.

27. Monroe AT, Bhandare N, Morris CG, Mendenhall WM. Preventing radiation retinopathy with hyperfractionation. Int $J$ Radiat Oncol Biol Phys. 2005;61:856-64.

28. Nikoskelainen $E$, Joensuu $M$. Retinopathy after irradiation for Graves' ophthalmopathy. Lancet. 1989;2:690-1.
29. Miller ML, Goldberg SH, Bullock JD. Radiation retinopathy after standard radiotherapy for thyroid-related ophthalmopathy. Am J Ophthalmol. 1991;112:600-1.

30. Brewington BY, Shao YF, Davidorf FH, Cebulla CM. Brachytherapy for patients with uveal melanoma: historical perspectives and future treatment directions. Clin Ophthalmol. 2018;12:925-34.

31. Takiar V, Voong KR, Gombos DS, et al. A choice of radionuclide: comparative outcomes and toxicity of ruthenium-106 and iodine-125 in the definitive treatment of uveal melanoma. Pract Radiat Oncol. 2015;3:e169-76.

32. Viebahn M, Barricks ME, Osterloh MD. Synergism between diabetic and radiation retinopathy: case report and review. Br J Ophthalmol. 1991:75:629-32.

33. Packer $\mathrm{S}$, Rotman M. Radiotherapy of choroidal melanoma with iodine-125. Ophthalmology. 1980;87:582-90.

34. Wakelkamp IMMJ, Tan H, Saeed P, et al. Orbital irradiation for Graves' ophthalmopathy: is it safe? A long-term follow-up study. Ophthalmology. 2004;111:1557-62.

35. Stack R, Elder M, Abdelaal A, et al. New Zealand experience of 1125 brachytherapy for choroidal melanoma. Clin Experiment Ophthalmol. 2005:33:490-4.

36. Kinyoun $\mathrm{JL}$, Lawrence BS, BarloW WE. Proliferative radiation retinopathy. Arch Ophthalmol. 1996;114:1097-100.

37. Hykin PG, Shields CL, Shields JA, Arevalo JF. The efficacy of focal laser therapy in radiation-induced macular edema. ophthalmology. 1998;105:1425-9.

38. Kinyoun IL. Long-term visual acuity results of treated and untreated radiation retinopathy (an AOS thesis). Trans Am Ophthalmol Soc. 2008:106:325-35.

39. Bakri SJ, Beer PM. Photodynamic therapy with verteporfin for classic choroidal neovascularization secondary to focal laser photocoagulation for radiation retinopathy. Ophthalmic Surg Lasers Imaging. 2003;34:475-7.

40. Bakri SJ, Beer PM. Photodynamic therapy for maculopathy due to radiation retinopathy. Eye (Lond). 2005;19:795-9.

41. Lee SC, Song JH, Chung EJ, Kwon OW. Photodynamic therapy of subretinal neovascularization in radiation retinopathy. Eye (Lond). 2004;18:745-6.

42. Sutter FKP. Intravitreal triamcinolone for radiation-induced macular edema. Arch Ophthalmol. 2003;121:1491.

43. Shields $\mathrm{CL}$, Demirci $\mathrm{H}$, Dai V, et al. Intravitreal triamcinolone acetonide for radiation maculopathy after plaque radiotherapy for choroidal melanoma. Retina. 2005;25:868-74.

44. Shields $\mathrm{CL}$, Demirci $\mathrm{H}$, Marr BP, et al. Intravitreal triamcinolone acetonide for acute radiation papillopathy. Retina. 2006;26:537-44.

45. Russo A, Avitabile T, Uva M, et al. Radiation macular edema after Ru-106 plaque brachytherapy for choroidal melanoma resolved by an intravitreal dexamethasone $0.7-\mathrm{mg}$ implant. Case Rep Ophthalmol. 2012;3:71-6

46. Hellman JB, Garcia-Gonzalez JM, Lewis S, Hariprasad SM Dexamethasone $0.7 \mathrm{mg}$ implant for the treatment of recalcitrant radiation maculopathy after proton radiotherapy for carcinoma of the maxillary sinus. J Ocul Dis Ther. 2014;2:30-5.

47. Baillif S, Maschi C, Gastaud P, Caujolle JP. Intravitrea dexamethasone 0.7-mg implant for radiation macular edema after proton beam therapy for choroidal melanoma. Retina. 2013;33:1784-90

48. Kaplan RI, Chaugule SS, Finger PT. Intravitreal triamcinolone acetate for radiation maculopathy recalcitrant to high-dose intravitreal bevacizumab. Br I Ophthalmol. 2017:101:1694-8.

49. Bakri SJ, Larson TA. The variable efficacy of intravitreal bevacizumab and triamcinolone acetonide for cystoid macular edema due to radiation retinopathy. Semin ophthalmol. 2015;30:276-80.

50. Finger PT, Chin KJ, Semenova EA. Intravitreal anti-VEGF therapy for macular radiation retinopathy: a 10-year study. Eur J Ophthalmol. 2016;26:60-6.

51. Gupta A, Muecke JS. Treatment of radiation maculopathy with intravitreal injection of bevacizumab (Avastin). Retina. 2008;28:964-8.

52. Jutley G, Shona OA, Leen RC, et al. Response to ranibizumab following tachyphylaxis to bevacizumab in a patient with radiation maculopathy following stereotactic fractionated radiotherapy for optic nerve meningioma. Arch Ophthalmol 2012;130:1466-70

53. Mashayekhi A, Rojanaporn D, Al-Dahmash S, et al. Monthly intravitreal bevacizumab for macular edema after iodine-125 plaque radiotherapy of uveal melanoma. Eur J Ophthalmol. 2014;24:228-34.

54. Mason JO, Albert MA, Persaud TO, Vail RS. Intravitrea bevacizumab treatment for radiation macular edema after plaque radiotherapy for choroidal melanoma. Retina. 2007:27:903-7

55. Shah NV, Houston SK, Markoe AM, et al. Early SD-OCT diagnosis followed by prompt treatment of radiation maculopathy using intravitreal bevacizumab maintains functional visual acuity. Clin Ophthalmol. 2012;6:1739-48.

56. Gondo M, Sakai T, Tsuneoka H, Kanehira C. Intravitrea bevacizumab for delayed radiation maculopathy and papillopathy after irradiation for maxillary sinus cancer. Clin Ophthalmol. 2011:5:1217-9.

57. Caujolle JP, Maschi C, Freton A, et al. Treatment of neovascular glaucoma after proton therapy for uveal melanomas with ranibizumab injection: preliminary results. Ophthalmic Res. 2012;47:57-60

58. Dunavoelgyi R, Zehetmayer M, Simader C, Schmidt-Erfurth U. Rapid improvement of radiation-induced neovascular glaucoma and exudative retinal detachment after a single intravitreal ranibizumab injection. Clin Exp Ophthalmol. 2007;35:878-80.

59. Nagendran ST, Finger PT. Anti-VEGF intravitreal bevacizumab for radiation-associated neovascular glaucoma. Ophthalmic Surg Lasers Imaging Retina. 2015;46:201-7.

60. Vásquez LM, Somani S, Altomare F, Simpson ER. Intracamera bevacizumab in the treatment of neovascular glaucoma and exudative retinal detachment after brachytherapy in choroidal melanoma. Can J Ophthalmol. 2009;44:106-7.

61. Yeung SN, Paton KE, Waite C, Maberley DA. Intravitreal bevacizumab for iris neovascularization following proton beam irradiation for choroidal melanoma. Can J Ophthalmol. 2010;45:269-73

62. Finger PT, Kurli M. Laser photocoagulation for radiation retinopathy after ophthalmic plaque radiation therapy. Br J Ophthalmol. 2005;89:730-8.

63. Shah SU, Shields CL, Bianciotto CG, et al. Intravitreal bevacizumab at 4-month intervals for prevention of macular edema after plaque radiotherapy of uveal melanoma. Ophthalmology. 2014;121:269-75.

64. Shields CL, Dalvin LA, Chang M, et al. Visual outcome at 4 years following plaque radiotherapy and prophylactic intravitrea bevacizumab (every 4 months for 2 years) for uveal melanoma: comparison with nonrandomized historical control individuals. JAMA Ophthalmol. 2019; 2019;138:136-46.

65. Horgan N, Shields CL, Mashayekhi A, et al. Periocular triamcinolone for prevention of macular edema after plaque radiotherapy of uveal melanoma: a randomized controlled trial. ophthalmology. 2009;116:1383-90

66. Materin MA, Bianciotto CG, Wu C, Shields CL. Sector laser photocoagulation for the prevention of macular edema after plaque radiotherapy for uveal melanoma: a pilot study. Retina. 2012;32:1601-7.

67. McCannel TA, McCannel CA. Iodine 125 brachytherapy with vitrectomy and silicone oil in the treatment of uveal melanoma: 1-to-1 matched case-control series. Int J Radiat Oncol Biol Phys. 2014:89:347-52.

68. Finger PT, Chin KJ. High-dose (2.0 mg) intravitreal ranibizumab for recalcitrant radiation retinopathy. Eur J Ophthalmol. 2013;23:850-6

69. Fung AT, Kumar N, Vance SK, et al. Pilot study to evaluate the role of high-dose ranibizumab $2.0 \mathrm{mg}$ in the management of neovascular age-related macular degeneration in patients with persistent/recurrent macular fluid $<30$ days following treatment with intravitreal anti-VEGF therapy (the LAST study). Eye (Lond). 2012;26:1181-7.

70. Bressler SB, Liu D, Glassman AR, et al. Change in diabetic retinopathy through 2 years: secondary analysis of a randomized clinical trial comparing aflibercept, bevacizumab, and ranibizumab. JAMA Ophthalmol. 2017;135:558.

71. Schefler AC, Fuller D, Anand R, et al. Randomized trial of monthly versus as-needed intravitreal ranibizumab for radiation retinopathy-related macular edema: 1 year outcomes. Am J Ophthalmol. 2020;S0002-9394(20)30157-4.

72. CATT Research Group, Martin DF, Maguire MG, et al. Ranibizumab and bevacizumab for neovascular age-related macular degeneration. N Eng/ J Med. 2011;364:1897-908.

73. Payne JF, Wykoff CC, Clark WL, et al. Randomized trial of treat and extend ranibizumab with and without navigated laser for diabetic macular edema. Ophthalmology. 2017;124:74-81.

74. Fallico M, Reibaldi M, Avitabile T, et al. Intravitreal aflibercept for the treatment of radiation-induced macular edema after ruthenium 106 plaque radiotherapy for choroidal melanoma. Graefes Arch Clin Exp Ophthalmol. 2019;257:1547-54.

75. Murray TG, Latiff A, Villegas VM, Gold AS. Aflibercept for radiation maculopathy study: a prospective, randomized clinical study. Ophthalmol Retina. 2019;3:561-6.

76. Wykoff CC, Clark WL, Nielsen JS, et al. Optimizing anti-VEGF treatment outcomes for patients with neovascular age-related macular degeneration. J Manag Care Spec Pharm. 2018;24(2-a Suppl.):S3-15.

77. US National Library of Medicine. ClinicalTrials.gov. Intravitreal aflibercept injection for radiation retinopathy trial (ARRT). 2017. Available at: https://clinicaltrials.gov/ct2/show/NCT03085784 (accessed May 6, 2020). 